\title{
EFEKTIFITAS PENGETAHUAN DALAM UPAYA PENCEGAHAN OSTEOPOROSIS PADA WANITA USIA 45 -60 TAHUN
}

\author{
Siti Maesaroh ${ }^{1, *}$, Ani Nur Fauziah ${ }^{2}$ \\ ${ }^{1,2}$ STIKES Mamba'ul 'Ulum Surakarta \\ ${ }^{1}$ mae_saroh71@yahoo.co.id*
}

\begin{abstract}
Abstrak
Latar Belakang : Penelitian dari Internasional Osteoporosis Foundation (IOF) mengungkapkan bahwa 1 dari 4 perempuan di Indonesia dengan rentang usia 5080 tahun memiliki resiko osteoporosis.Resiko osteoporosis perempuan di Indonesia 4 kali lebih tinggi dibandingkan laki laki. Osteoporosis merupakan salah satu penyakit yang digolongkan dalam penyakit Silent Epidemic Disease karena tidak menunjukkan gejala gejala yang spesifik.

Tujuan : penelitian ini bertujuan untuk mengetahui hubungan antara pengetahuan tentang osteoporosis dengan upaya yang dilakukan untuk mencegah osteoporosis pada wanita usia 45-60 tahun.

Metode :Penelitian ini mengguanakan penelitian diskriptif analitik dengan pendekatan Cross Sectional. Populasi penelitian ini adalah semua wanita usia 45 60 tahun di desa Jetis Juwiring Klaten pada bulan Februari 2020, teknik sampling yang digunakan adalah Accidental Sampling dimana saat penelitian dijumpai responden sebanyak 58 responden. Data diambil menggunakan data primer yaitu responden mengisi kuesioner dan data sekunder berupa Kartu Tanda Penduduk atau Kartu keluarga untuk mengetahui usia. Alat pengumpulan data berupa kuesioner. Analisa data menggunakan uji korelasi Somers'd menggunakan program SPSS
\end{abstract}

Hasil : mayoritas responden berpendidikan SMA sebanyak 51,7\% dan mayoritas berumur 51-55 tahun sebanyak 38\%. Pengetahuan responden mayoritas dalam kategori cukup $(51,7 \%)$, upaya pencegahan osteoporosis yang dilakukan responden mayoritas dalam kategori cukup $(51,7 \%)$. Sedangkan hasil koefisien korelasi Somers'dsebesar 0,752dengan signifikan 0,000

Simpulan : pengetahuan sangat efektif dalam upaya pencegahan osteoporosis yang dilakukan wanita usia 45-60 tahun.

Kata Kunci: pengetahuan; pencegahan osteoporosis.

\section{EFFECTIVENESS OF KNOWLEDGE IN THE PREVENTION OF OSTEOPOROSIS IN WOMEN AGE 45 -60 YEARS}

\begin{abstract}
Background : Research from the International Osteoporosis Foundation (IOF) reveals that 1 in 4 women in Indonesia with an age range of 50-80 years have a risk of osteoporosis. The risk of osteoporosis for women in Indonesia is four times higher than that of men. Osteoporosis is a disease that is classified as Silent Epidemic Disease because it does not show specific symptoms.
\end{abstract}


The purpose : The purpose of this study was to determine the relationship of knowledge about osteoporosis with the efforts made to prevent osteoporosis in women aged 45-60 years.

Method :This research method used descriptive analytic research with Cross Sectional approach. The study population was all women aged 45 - 60 years in the village of Jetis Juwiring Klaten in February 2020. The sampling technique used was Accidental Sampling where 58 respondents were found during the study. Data was taken using primary data and secondary data. Data collection tool in the form of a questionnaire. Data analysis uses Somers' correlation test using the SPSS program

Result : The results of this study were the majority of respondents with a high school education of 51.7\% and the majority aged 51-55 years. The majority of respondents' knowledge is in the sufficient category(51,7\%), the prevention of osteoporosis by the majority respondents in the sufficient knowledge is very effective in efforts to prevent osteoporosis by women aged 45-60 year category (51.7\%). While the Somers'd correlation coefficient resulted 0.752 with a significant 0,000

Conclusion : knowledge is very effective in efforts to prevent osteoporosis by women aged 45-60 year.

Keywords: knowledge; prevention of osteoporosis

\section{PENDAHULUAN}

Osteoporosis merupakan salah satu penyakit degeneratif. Penelitian dari internasional osteoporosis foundation (IOF) mengungkapkan bahwa 1 dari 4 perempuan di Indonesia dengan rentang usia 50-80 tahun memiliki resiko osteoporosis. Dan resiko osteoporosis perempuandi Indonesia 4kali lebih tinggi dibandingkan laki laki. Biasanya penyakit keropos tulang ini menjangkiti sebagian besar wanita pasca menopause.Osteoporosis tidak menampakkan gejala gejala fisik yang nyata hingga terjadi keropos atau keretakan tulang pada usia senja. Hilangnya hormon estrogen setelah menopause meningkatkan resiko terkena osteoporosis. Osteoporosis pada wanita dipengaruhi oleh hormon estrogen. Namun karena gejala baru muncul setelah usia 50 tahun, osteoporosis tidak mudah dideteksi secara dini.(Kemenkes RI, 2015)

Osteoporosis di jumpai di seluruh dunia dan sampai saat ini masih merupakan masalah kesehatan dalam masyarakat terutama di negara yang sedang berkembang. Di Amerika Serikat osteoporosis menyerang 20-30 juta penduduk, 1 diantara 2-3 wanita post menopause dan lebih dari $50 \%$ penduduk diatas usia 7580 tahun. Data dari WHO menunjukkan bahwa di seluruh dunia terdapat sekitar 200 juta orang yang menderita osteoporosis. Pada tahun 2050 diperkirakan angka patah tulang panggulmeningkat dua kali lipat pada wanita dan tiga kali lipat pada pria. Laporan WHO juga menunjukkan bahwa 50\% patah tulang adalah patah tulang paha atas yang dapat mengakibatkan kecacatan seumur hidup dan kematian. Dibandingkan dengan masyarakat di negara - negara Afrika densitas tulang masyarakat eropa dan Asia lebih rendah, sehingga lebih mudah mengalami osteoporosis. Hasil penelitian White Paper yang dilaksanakan bersama 
perhimpunan osteoporosis Indonesia tahun 2007 melaporkan bahwa proporsi penderita osteoporosis pada penduduk berusia di atas 50 tahun adalah 32,3\% pada wanita dan 28,8\% pada pria. ( Kemenkes RI,2015)

Osteoporosis merupakan salah satu penyakit yang digolongkan dalam penyakit silent disease karena tidak menunjukkan gejala gejala yang spesifik. Gejala dapat gerupa nyeri pada tulang dan otot, terutama sering terjadi pada punggung. Beberapa gejala osteoporosis mulai dari patah tulang, tulang punggung yang semakin membungkuk, menurunnya tinggi badan dan nyeri punggung.Kemenkes RI, 2015)

Untuk mencegah terjadinya osteoporosis ada beberapa langkah yang dapat dilakukan yaitu mencukupi asupan kalsium, mencukupi asupan vitamin D melalui pajanan sinar matahari pagi atau sore, sinar matahari akan mengubah pro vitamin Dyang adadi bawah kulitmenjadi vitamin D, hidup aktif dengan cara melakukan aktifitas fisikdengan prinsip pembebanan terhadap tulang dengan bentuk perbanyak jalan. Selain itu hindari merokok, minum alkohol, waspada jika terdapat garis keturunan adayang menderita osteoporosis. Pencegahan osteoporosis harus dimulai sejak bayi dalam kandungan, masa kanak kanak, remaja, sampai dewasa. (Kemenkes RI 2015)

Ada hubungan yang bermakna antara pengetahuan pra lansia dengan upaya pencegahan osteoporosis

Osteoporosis seharusnya dapat dicegah dengan membudayakan perilaku hidup yang sehat yang intinya dengan mengkonsumsi makanan bergizi seimbang yang memenuhi kebutuhan gizi, kaya serat, rendah lemak dan kaya kalsium. Pengetahuan tentang osteoporosis sangat penting agar dapat melakukan upaya upaya pencegahan terjadinya osteoporosis sejak dini baik untuk diri sendiri, keluarga dan masyarakat. Usahakan untuk mencapai kepadatan tulang semaksimal mungkin sebelum usia 34 tahun, karena kepadatan tulang akan menurun setelah mencapai usia itu. Oleh karena itu, sejak muda harus "menabung" untuk memperkuat kepadatan tulang. (Kemenkes RI, 2019)

Di desa Jetis dijumpai kasus patah tulang pada wanita usia lanjut, yaitu patah tulang paha dan patah tulang panggul, dimana pada kasus tersebut tidak dapat dilakukan tindakan operasi, karena kondisi kesehatan lansia tersebut tidak memungkinkan. Terjadinya patah tulang pada lansia tersebut dipicu karena jatuh saat berjalan di linkungan rumah. Berdasarkan penelitian terdapat hubungan yang bermakna antara pengetahuan pra lansia dengan upaya pencegahan osteoporosis. (Amelia W., 2018)

Dari uraian diatas penulis tertarik melakukan penelitian tentang "Efektifitas Pengetahuan dalam Upaya Pencegahan Osteoporosis pada wanita usia 45 - 60 tahun"

\section{METODE}

Metode yang digunakan dalam penelitian ini adalah diskriptif analitik, dengan pendekatan cross sectional.Populasi dalam penelitian ini adalah wanita usia 45 60 tahun di desa Jetis Juwiring Klaten pada bulan Februari 2020, teknik sampling yang digunakan adalah Accidental Sampling dimana saat penelitian dijumpai responden sebanyak 58 responden.Alat pengumpulan data pada penelitian ini 
adalah menggunakan kuesioner bersifat tertutup, dimana responden memilih atau menjawab pada jawaban yang sudah ada. Metode pengumpulan data yang digunakan adalah data primer yaitu data yang diperoleh langsung dari responden dengan mengisi kuesioner dan skunder yaitu data dari kartu keluarga atau Kartu tanda penduduk. Dalam penelitian ini uji analisis data dengan analisa univariat dan analisa bivariat yang digunakan adalah uji Korelasi Somers'd dengan menggunakan SPSS

HASIL DAN PEMBAHASAN

Tabel 1. Distribusi Frekuensi relatif responden berdasarkan pendidikan

\begin{tabular}{clccc}
\hline No & & Usia & Frekuensi & Prosentase (\%) \\
\hline 1 & SD & 2 & 3,4 \\
2 & SMP & 10 & 17,2 \\
3 & SMA & 30 & 51,7 \\
4 & Perguruan Tinggi & 16 & 28 \\
\hline & Jumlah & 58 & $100 \%$ \\
\hline
\end{tabular}

Pada tabel 1 menunjukkan pendidikan responden mayoritas SMA berjumlah 30 responden $(51,7 \%)$.

Tabel 2. Distribusi frekwensi relatif responden berdasarkan usia

\begin{tabular}{ccccc}
\hline No & & Umur & Frekuensi & Prosentase (\%) \\
\hline 1 & $45-50$ & & 18 & 31 \\
2 & $51-55$ & & 22 & 38 \\
3 & $56-60$ & & 18 & 31 \\
\hline & & 58 & $100 \%$ \\
\hline
\end{tabular}

Berdasarkan tabel 2 di atas menunjukkan responden mayoritas pada umur 51-55 tahun sebanyak 22 responden (38\%)

Tabel 3. Distribusi Frekuensi relatif Pengetahuan responden Tentang osteoporosis

\begin{tabular}{llccc}
\hline No & & Pengetahuan & Frekuensi & Prosentase (\%) \\
\hline 1 & Kurang & 6 & 10,3 \\
2 & Cukup & 30 & 51,7 \\
3 & Baik & 22 & 37,9 \\
\hline & & Jumlah & 58 & $100 \%$ \\
\hline
\end{tabular}

Pada Tabel 3 menunjukkan pengetahuan tentang osteoporosis pada 58 responden mayoritas dalam kategori cukup sebanyak 30 responden $(51,7 \%)$.

Tabel 4. Distribusi frekwensi pengetahuan tentang osteoporosis berdasarkan pendidikan responden

\begin{tabular}{llcccccc}
\hline \multirow{2}{*}{ No } & Pendidikan & \multicolumn{6}{c}{ Pengetahuan } \\
\cline { 2 - 8 } & & \multicolumn{2}{c}{ Baik } & \multicolumn{2}{c}{ Cukup } & \multicolumn{2}{c}{ Kurang } \\
\cline { 2 - 8 } & f & \% & f & \% & f & \% \\
\hline 1 & SD & 0 & 0 & 0 & 0 & 2 & 33,3 \\
2 & SMP & 0 & 0 & 8 & 26,7 & 2 & 33,3 \\
3 & SMA & 8 & 36,4 & 20 & 66,7 & 2 & 33,3 \\
4 & Perguruan Tinggi & 14 & 63,6 & 2 & 6,7 & 0 & 0 \\
\hline
\end{tabular}




\begin{tabular}{ccccccc}
\hline Jumlah & 22 & 100 & 30 & 100 & 6 & 100 \\
\hline
\end{tabular}

Berdasarkan tabel 4 dapat diketahui responden yang memilikipengetahuan baik sebagian besar berpendidikan perguruan Tinngi sebanyak 14 orang $(63,6 \%)$. Responden dengan pengetahuan cukup mayoritas berpendidikan SMA 20 orang $(66,7 \%)$. Responden dengan pengetahuan kurang berpendidikan SD, SMP dan SMA masing masing 2 orang $(33,3 \%)$.

Tabel 5. Distribusi frekwensi Pengetahuan tentang osteoporesis berdasarkan usia responden

\begin{tabular}{llcccccc}
\hline & \multirow{2}{*}{ No } & \multicolumn{6}{c}{ Pengetahuan } \\
\cline { 3 - 8 } & & \multicolumn{2}{c}{ Baik } & \multicolumn{2}{c}{ Cukup } & \multicolumn{2}{c}{ Kurang } \\
\cline { 3 - 8 } & & $\mathbf{f}$ & \% & f & \% & f & \% \\
\hline 1 & $45-50$ & 6 & 27,3 & 12 & 40 & 0 & 0 \\
2 & $51-55$ & 6 & 27,3 & 16 & 53,3 & 6 & 100 \\
3 & $56-60$ & 8 & 36,4 & 8 & 26,7 & 0 & 0 \\
\hline \multicolumn{2}{l}{ Jumlah } & 22 & 100 & 30 & 100 & 6 & 100 \\
\hline
\end{tabular}

Berdasarkan tabel 5 dapat diketahui responden dengan pengetahuan baik sebagian besar pada umur 56-60 tahun sebanyak 8 responden (36,4\%). Responden dengan pengetahuan cukup mayoritas berumur 51-60 tahun sebanyak 16 orang $(53,3 \%)$. Responden dengan pengetahuan kurang semuanya berumur 51-60 tahun

Tabel 6. Distribusi frekwensi upaya pencegahan osteoporosis yang dilakukan

\begin{tabular}{llccc}
\multicolumn{5}{c}{ responden } \\
\hline No & & Upaya pencegahan & Frekuensi & Prosentase (\%) \\
\hline 1 & Kurang & 4 & 6,9 \\
2 & Cukup & 30 & 51,7 \\
3 & Baik & 24 & 41,4 \\
\hline & Jumlah & 58 & 100 \\
\hline
\end{tabular}

Pada tabel 6 di atas dapat diketahui upaya pencegahan yangdilakukan responden sebagian besar mayoritas dalam kategori cukup sebanyak 30 responden $(51,7 \%)$

Tabel 7. Distribusi frekwensi upaya pencegahan osteoporosis yang dilakukan responden berdasarkan pendidikan

\begin{tabular}{llcccccc}
\hline \multirow{2}{*}{ No } & \multirow{2}{*}{ Pendidikan } & \multicolumn{7}{c}{ Upaya pencegahan } \\
\cline { 3 - 7 } & & Baik & Cukup & \multicolumn{2}{c}{ Kurang } \\
\cline { 2 - 7 } & SD & 0 & 0 & 0 & 0 & 2 & 50 \\
2 & SMP & 0 & 0 & 8 & 26,7 & 2 & 50 \\
3 & SMA & 8 & 33,3 & 22 & 73,3 & 0 & 0 \\
4 & Perguruan Tinggi & 16 & 66,6 & 0 & 0 & 0 & 0 \\
\hline & Jumlah & 24 & 100 & 30 & 100 & 4 & 100 \\
\hline
\end{tabular}

Berdasarkan tabel 7. di atas dapat diketahui upaya pencegahan dalam kategori baik mayoritas dilakukan responden dengan pendidikan perguruan tinggi sebanyak 16 responden $(66,6 \%)$. Upaya pencegahan dalam kategori cukup mayoritas dilakukan responden dengan pendidikan SMA sebanyak 22 responden 
(73,3\%). Sedangkan upaya pencegahandalam kategori kurang dilakukan responden dengan pedidikan SD dan SMP masing- masing 2 responden (50\%).

Tabel 8. Distribusi frekwensi upaya pencegahan yang dilakukan berdasarkan usia responden

\begin{tabular}{|c|c|c|c|c|c|c|c|}
\hline \multirow{3}{*}{ No } & \multirow{3}{*}{ Umur } & \multicolumn{6}{|c|}{ Upaya pencegahan } \\
\hline & & \multicolumn{2}{|c|}{ Baik } & \multicolumn{2}{|c|}{ Cukup } & \multicolumn{2}{|c|}{ Kurang } \\
\hline & & $\mathbf{f}$ & $\%$ & $\mathbf{f}$ & $\%$ & $\mathbf{f}$ & $\%$ \\
\hline 1 & $45-50$ & 4 & 16,7 & 14 & 46,7 & 2 & 50 \\
\hline 2 & $51-55$ & 8 & 33,3 & 12 & 40 & 0 & 0 \\
\hline 3 & $56-60$ & 12 & 50 & 4 & 13,3 & 2 & 50 \\
\hline & Jumlah & 24 & 100 & 30 & 100 & 4 & 100 \\
\hline
\end{tabular}

Berdasarkan tabel 8. dapat diketahui upaya pencegahan dalam kategori baik dilakukan responden mayoritas berumur 56-60 tahun sebanyak 12 responden (50\%). Upaya pencegahandalam kategori cukup, mayoritas dilakukan responden berumur 45-50 tahun sebanyak 14 responden(46,7\%)

Tabe1 9. Tabulasi Silang Hubungan Pengetahuan dengan Upaya pencegahan osteoporosis

\begin{tabular}{|c|c|c|c|c|c|c|c|c|c|}
\hline \multirow{3}{*}{$\begin{array}{c}\text { Upaya } \\
\text { pencegahan }\end{array}$} & \multicolumn{6}{|c|}{ Pengetahuan } & \multirow{3}{*}{ Total } & \multirow{3}{*}{$\%$} & \multirow{3}{*}{$\begin{array}{l}\text { Hasil uji } \\
\text { Somers'd }\end{array}$} \\
\hline & \multicolumn{2}{|c|}{ Baik } & \multicolumn{2}{|c|}{ Cukup } & \multicolumn{2}{|c|}{ Kurang } & & & \\
\hline & $\mathbf{F}$ & $\%$ & $\mathbf{F}$ & $\%$ & $\mathbf{F}$ & $\%$ & & & \\
\hline Baik & 20 & 34,5 & 4 & 6,9 & 0 & 0 & 24 & 41,4 & Corelation \\
\hline Cukup & 2 & 3,4 & 24 & 41,4 & 4 & 6,9 & 30 & 51,7 & $\begin{array}{c}\text { coeficient } \\
0752\end{array}$ \\
\hline Kurang & 0 & 0 & 2 & 3,4 & 2 & 3,4 & 4 & 6,9 & Significant \\
\hline Total & 22 & 37,9 & 30 & 51,7 & 6 & 10,3 & 58 & 100 & 0,001 \\
\hline
\end{tabular}

Pada Tabel 9. menunjukkan responden dengan pengetahuan baik mayoritas melakukan upaya pencegahan osteoporosis dalam kategori baik sebanyak 20 responden $(34,5 \%)$. Responden dengan dengan pengetahuan cukup mayoritas melakukan upaya pencegahan dalam kategori cukup sebanyak 24 responden $(41,4 \%)$. Sedangkan responden dengan pengetahuan kurang mayoritas melakukan pencegahan osteoporosis dalam kategori cukup sebanyak 4 orang $(6,9 \%)$

Responden dalam penelitian ini adalah wanita usia 45-60 tahun. Berdasarkan tabel1 diketahui bahwa responden sebagian besar berpendidikan SMA yaitu 30 responden $(51,7 \%)$. Hal ini berarti sebagian besarresponden memiliki jenjang pendidikan menegah.

Berdasarkan tabel 2 reponden sebagian besar berusia 51-55 tahun. Usia seseorang juga berpengaruh terhadap daya pikir seseorang. Pengetahuan dipengaruhi beberapa faktor diantaranya adalah usia Usia menggambarkan kematangan fisik, psikis dan sosial yang mempengaruhi proses belajar mengajar. Ini berarti bahwa usia merupakan salah satu faktor yang mempengaruhi penangkapan informasi yang pada akhirnya berpengaruh pada peningkatan pengetahuan seseorang, termasuk pengetahuan tentang osteoporosis. (Wawan A., 2010) 
Berdasarkan tabel 3 diketahui pengetahuan tentang osteoporosis responden mayoritas dalam kategori cukup sebanyak 30 responden (51,7\%). Hasil penelitian ini berbeda dengan hasil penelitian yang dilakukan Ayu Lestari Nofiyanti dkk. dengan judul Hubungan Pengetahuan dan Sikap Osteoporosis pada Pegawai Administrasi Wanita di Universitas Lampung dimana sebagian besar responden memiliki pengetahuan baik sebanyak 99 responden(86,84\%). (Nofoyanti AL. Dkk, 2015) Hasil penelitian ini berbeda juga dengan penelitian yang dilakukan oleh Esti Widyastuti dkk. dengan judul Hubungan Pengetahuan Lansia tentang Osteoporosis terhadap Pelaksanaan Senam Lansia, dimana sebagian besar responden memiliki pengetahuan kurang yaitu sebanyak 36 responden (58\%). (Widyastuti, E, 2011) Hal ini disebabkan karena karakteristik responden yang berbeda. Pada penelitian ini responden berusia 45-60 tahun, pada penelitian oleh Ayu Lestari Nofiyanti dkk. responden berusia 20-55 tahun, dan pada penelitian oleh Esti Widyastutu responden berusia 60-80tahun

Pengetahuan atau kognitif merupakan domain yang sangat penting untuk terbentuknya tindakan seseorang (over behavior).Pengetahuan merupakan hasil tahu dan hal ini terjadi setelah orang melakukan penginderaan terhadap sesuatu objek tertentu. Penginderaan terjadi melalui panca indra manusia yaitu indra penglihatan, pendengaran, penciuman, peraba, dan perasa. Sebagian besar pengetahuan diperoleh melalui mata, telinga, pengetahuan atau kognitif merupakan domain yang sangat penting untuk terbentuknya tindakan seseorang.(Notoatmodjo S., 2012)

Pengetahuan dipengaruhi oleh faktor internal dan eksternal. Faktor internal yang mempengaruhi pengetahuan seseorang antara lain pendidikan, pekerjaan dan umur. Faktor eksternal yang mempengaruhi pengetahuan seseorang antara lain lingkungan dan sosial budaya. (Wawan A. 2010)

Pada tabel 4 menunjukkan responden dengan pengetahuan baik sebagian besar berpendidikan perguruan tinggi $(63,6)$. Dan tabel 5menunjukkan responden dengan pengetahuan baik mayoritas berusia 55-60 tahun (36,4\%). Pengetahuan ini dipengaruhi oleh pendidikan. Makin tinggi pendidikan seseorang, maka makin mudah menerima informasi sehingga makin banyak pula pengetahuan yang dimiliki. Umur mempengaruhi daya tangkap dan pola pikir. Semakin cukup umur, tingkat kematangan dan kekuatan seseorang akan lebih matang dalam berfikir dan bekerja ini dikarenakan pada usia tersebut lebih giat semangat untuk mencari pengalaman yang lebih banyak. Semakin bertambahnya usia seseorang semakin membaik pola pikirnya akan tetapi semakin tua daya tangkap seseorang akan menurun. Umur semakin tua semakin bijaksana, semakin banyak informasi yang dijumpai dan semakin banyak hal yang dikerjakan sehingga menambah pengalaman. (Wawan A., 2010)

Pengetahuan merupakan sesuatu yang sangat penting untuk dimiliki agar dapat melakukan ukan upaya pencegahan osteoporosis yang biasa terjadi pada wanita terutama yang sudah memasuki menopause.

Pada tabel 6. dapat dilihat upaya pencegahan terhadap osteoporosis mayoritas dalam kategori cukup yaitu sebesar 30 responden (51,7\%). Hasil penelitian ini berbeda dengan hasil penelitian oleh Wachyu Amelia dengan judul Hubungan pengetahuan dan konsumsi susu pada wanita pra lansia dengan upaya 
pencegahan osteoporosis di batu raja tahun 2018 dimana sebagian besar upaya pencegahan yang dilakukan responden dalam kategori baik yaitu sebanyak 41 responden $(55,4 \%) .{ }^{9}$ Sedangkan hasil penelitian Rajaratenam dkk. menunjukkan tindakan pencegahan osteoporosis dalam kategori baik $(88,5 \%)$. (Rajaratenam SG.,2014)

Upaya pencegahan osteoporosis merupakan tindakan yang dilakukan responden untuk mencegah terjadinya osteoporosis. Upaya pencegahan osteoporosis hendaknya memperhatikan kondisi puncak massa tulang, dimana kondisi tersebut optimal pada masa dewasamuda. Dengan tercapainya puncak massa tulang optimal pada masa dewasamuda, osteoporosis yang mungkin timbul pada usia tua akan lebih ringan.Pada umumnya puncak massa tulang akan tercapai pada usia 20 sampai30 tahun, setelah itu akan menurun penyebab utamanya adalah prosespenuaan, absorbsi kalsium menurun dan fungsi para tiroid meningkat. Kejadian oestoponia pada wanita dengan hipoestrogen akan menyebabkan kehilangan jaringan tulang pada wanita 2-3\% pertahun pada masa perimenipause dan hal ini berlangsung terus menerus sampai 5-10 tahunpasca menapause, sehingga mencapai ambang patah tulang. Setelah usia 65 tahun memasuki usia geriatri tetap terjadi kehilangan massa tulang dengan kecepatan yang lebih rendah. (Depkes RI, 2008)

Dari hasil tabulasi silang antara pengetahuan dan upaya pencegahan osteoporosis pada tabel 8 dapat diketahui bahwa hasil analisis efektifitas pengetahuan dalam upaya pencegahan osteoporosis dengan menggunakan uji korelasi Somers'd didapatkan hasil koefisien korelasinya 0,752 dengan nilai signifikansinya 0,000 . Hal ini dapat diartikan bahwa pengetahuan sangat efektif dalam upaya pencegahan osteoporosis yang dilakukan responden. Semakin baik pengetahuan responden tentang osteoporosis maka semakin baik pula upaya yang dilakukan reponden untuk mencegah osteoporosis.

Hasil penelitian ini sejalan dengan penelitian yang dilakukan oleh Esti Widyastuti dengan judul hubungan pengetahuan lansia tentang osteoporosis terhadap pelaksanaan senam lansia, dimana disimpulkan ada hubungan pengetahuan lansia tentang osteoporosis dengan pelaksanaan senam lansia. Senam lansia merupakan aktifitas fisik yang merupakan salah satu upaya pencegahan osteoporosis pada usia lanjut. (Widyastuti E., 2011)

Hasil penelitian ini juga sejalan dengan penelitian oleh Yasinta ES dkk. dengan judul hubungan pengetahuan lansia tentang osteoporosis dengan perilaku mengkonsumsi makanan berkalsium di panti wredha $\mathrm{X}$ Yogyakarta. Ada hubungan antara pengetahuan lansia tentang osteoporosis dengan perilaku mengkonsumsi makanan berkalsium, dimana perilaku mengkonsumsi makanan berkalsium merupakan upaya mencegah osteoporosis. (Soke YE. Dkk., 2016)

Penelitian lain yang yang dilakukan oleh Wachyu Amelia dengan judul hubungan pengetahuan dan konsumsi susu pada wanita pralansia dengan upaya pencegahan osteoporosis di batu raja tahun 2018 menyimpulkan bahwa ada hubungan yang positif antara pengetahuan pralansia dengan upaya pencegahan osteoporosis. (Amelia W., 2018)

Pengetahuan dipengaruhi oleh banyak faktor antara lain pendidikan, pekerjaan umur media masa atau sumber informasi, sosial budaya, ekonomi, 
lingkungan dan pengalaman. (Kholid A., 2012) Peningkatan pengetahuan masyarakat dapat ditempuh dengan pemberian informasi melaui penyuluhan secara langsung atau melaui media informasi misalnya leaflet, poster, radio, televisi atau media informasi yang lain. Peningkatan pengetahuan masyarakat akan berdampak pada perubahan perilaku termasuk di dalamnya upaya pencegahan yang dapat dilakukan mayarakat dalam mencegah osteoporosis.

Pencegahan osteoporosis dapat dilakukan dengan beberapa langkah yaitu cukupi asupan kalsium, cukup asupan vitamin D melalui pajanan sinar matahari pagi atau sore, matahari mengubah provitamin D yang ada di bawah kulit menjadi vitamin D, hidup aktif dengan melakukan aktifitas fisik, hindari merokok dan minum alkohol, waspada jika terdapat garis keturunan ada yang menderita osteoporosis dan melakukan pemeriksaan dini osteoporosis pada dokter saat menopause.( Kemenkes RI., 2015 )

\section{SIMPULAN}

Simpulan dalam penelitian ini adalah pengetahuan sangat efektif dalam upaya pencegahan osteoporosis pada wanita usia 45-60 tahun.

\section{SARAN}

Saran yang dapat peneliti sampaikan pada penelitian ini adalah diharapkan peneliti selanjutnya dapat meneliti tentang faktor - faktor yang mempengaruhi upaya pencegahan osteoporosis sehingga dapat diketahui faktor yang paling berpengaruh terhadap pencegahan osteoporosis

Diharapkan responden meningkatkan pengetahuan tentang osteoporosis melalui internet, buku, majalah, dan tenaga kesehatan sehingga kesadaran untuk melakukan upaya pencegahan osteoporosis menjadi lebih baik.

\section{DAFTAR PUSTAKA}

Amelia W. 2018. Hubungan pengetahuan dan konsumsi susu pada wanita pralansia dengan upaya pencegahan osteoporosis di Baturaja, Jurnal 'Aisyah Medika Volume 2

Departemen Kesehatan, Surat Keputusan Menteri Kesehatan Republik Indonesia nomor 1142/Menkes/Sk/XII/2008 tentang Pedoman pengendalian osteoporosis, Jakarta Departemen Kesehatan 2008 https://www.persi.or.id/images/regulasi/kepmenkes/kmk11422009.pdf

Kholid A. 2012. Promosi Kesehatan Dengan Pendekatan Teori Perilakumedia dan aplikasinya Jakarta: PT Raja Grafindo Persada

Kementrian Kesehatan RI. 2015. Data \& kondisi penyakit osteoporosis di Indonesia. Jakarta: Kemenkes RI

Kementrian Kesehatan RI. 2015. Data \& kondisi penyakit osteoporosis di Indonesia. Jakarta: Kemenkes RI

Kemenkes $\quad 2019.2$ Pencegahan Osteoporosis http://www.p2ptm.kemkes.go.id/infographic-p2ptm/penyakit-gangguanmetabolik/bagaimana-pencegahan-osteoporosis\# 
Misnadiarly, 2013. Osteoporosis Pengenalan Faktor Resiko Pencegahan Dan Pengobatan, Jakarta : Permata Puri Media

Nofiyanti AL dkk. 2015 Hubungan pengetahuan dan sikap terhadap osteoporosis. Jurnal Mayority, Volume 4 No 2

Notoatmodjo S. 2012. Kesehatan Masyarakat Ilmu dan Seni. Jakarta : Rineka Cipta

Rajaratenam SG. dkk. 2014. Hubungan tingkat pengetahuan dan sikap dengan tindakan pencegahan osteoporosis pada wanita usila di kelurahan jati, Jurnal Kesehatan Andalas. Volume 3 No 2

Soke YE. dkk. 2016. Hubungan pengetahuan lansia tentang osteoporosis dengan perilaku mengkonsumsi makanan berkalsiumdi panti Wredha $X$ Yogyakarta, Jurnal Keperawatan. Respati Vol III No 1

Wawan A dan M.Dewi. 2010. Teori dan Pengukuran Pengetahuan, Sikap, dan Perilaku Manusia. Yogyakarta : Nuha Medika Cipta

Widyastuti E. 2011. Hubungan pengetauan lansia tentang osteoporosisterhadap pelaksanaan senam lansia 